\title{
Women's Work and Divorce: A Matter of Anticipation? A Research Note
}

\author{
Anne-Rigt Poortman
}

The most common hypothesis on the positive association between wives' work and divorce is that the wife's work increases the risk of divorce. Critics argue that the causal direction is the other way around and that women adjust their working hours in anticipation of divorce. These competing hypotheses are tested by comparing the effects of wives' work between divorces that differ in the extent to which they were expected. Because women who do not expect to divorce are not able to adjust their working efforts prior to divorce, it is argued that, if anticipatory behaviour plays a role, the effect of wives' work should be smaller when the divorce was unexpected. The results lend weak support for anticipatory behaviour. The effect of wives' full-time work is smaller for unexpected divorces. However, the effect of full-time work is also relatively strong when the divorce was fully unexpected. Moreover, the effects of wives' work and working hours do not differ significantly between divorces varying in the extent to which they were expected. These findings suggest that there is something about wives' work that increases the divorce risk.

\section{Introduction}

The rise in women's labour force participation is often seen as responsible for increasing divorce rates (Becker, 1981; Cherlin, 1981; Ruggles, 1997a). Although results are mixed, various studies show that women who work or work more hours have a higher divorce risk (Bracher et al., 1993; Greenstein, 1990; South, 2001; Spitze and South, 1985). The most common interpretation is that wives' work leads to an increase in the risk of divorce. Critics, however, argue that the causal direction between wives' work and divorce is the other way around (Beck and Hartmann, 1999; Davis, 1984; Diekmann, 1994; Johnson and Skinner, 1986; Rogers, 1999); women adjust their working efforts, for example by entering the labour market, in anticipation of divorce. Such anticipatory behaviour would also lead to a positive association between wives' work and divorce.
The direction of the relationship between wives' work and divorce has rarely been examined so far, because this is not easy. The few existing studies use different methodologies. Two American studies apply statistical techniques to simultaneously estimate both directional effects and compare their relative strength. Rogers (1999) uses structural equation modelling to estimate the reciprocal paths between wives' income and marital quality. Johnson and Skinner (1986) estimate a simultaneous model of future divorce probabilities and wives' current employment. Findings show that the effect of the wife's work on the divorce risk (Johnson and Skinner, 1986) or the wife's income on marital quality (Rogers, 1999) is not significant and smaller than the reversed effect, which is significant. Both studies conclude that the positive association between wives' work and divorce is primarily because women increase their working efforts prior to divorce. 
A German study (Beck and Hartmann, 1999) is based on substantive reasoning; the effect of wives' work on divorce might be overestimated due to anticipatory behaviour and if so, the work effect should decrease when anticipatory behaviour is controlled for. They control for anticipatory behaviour by measuring wives' work prior to the moment that the marriage was perceived as being unstable; at that time women could not have yet responded to marital problems and reversed causation can therefore not be responsible for a work effect (see also Yamaguchi, 1991: 139). When comparing the effects of wives' work on divorce with and without controlling for anticipatory behaviour, the results show that the work effect is smaller when anticipatory behaviour is controlled for, suggesting that the work effect is partly due to wives' labour market reactions to a higher divorce risk. They also find that working women continue to have a significantly higher divorce risk when anticipatory behaviour is controlled for, which lends support for the idea that wives' employment increases the risk of divorce as well.

Both methodologies have their disadvantages. Simultaneous estimation of both effects requires statistical models, which may be vulnerable to identification problems and are based on strong distributional assumptions that are difficult to test. Furthermore, the model is based on the assumption that the estimated divorce risk, used as a predictor in the work-equation, reflects people's own perception of their future chances to divorce. Measuring wives' work prior to anticipatory behaviour has the problem that, if the wife's work refers to a moment further back in time, its effect may also be smaller for other reasons than anticipatory behaviour. For example, conflicts resulting from the wife's employment may have already been overcome during the time after the measurement moment, leading to an underestimation of the destabilizing influence of the wife's work when measured at an earlier moment.

I follow a different approach to test the two competing hypotheses. In a large-scale survey from the Netherlands, divorced respondents were retrospectively asked to what extent they expected the divorce. On the basis of substantive reasoning, this information can be used to examine the extent to which the two directional relationships are present, as will be explained in the following section.

\section{Hypotheses}

The most common interpretation for the relation between wives' work and divorce is that wives' work leads to a higher divorce risk. The assumption is that there is something about wives' work that makes divorce more likely (Greenstein, 1990). An economic argument is that the wife's employment decreases the efficiency gains of marriage stemming from task specialization (Becker, 1981). Another economic argument is that the wife's employment increases her financial independence, making it easier to divorce (Cherlin, 1979; Ruggles, 1997b). Also, husbands may more easily divorce when their wives are financially independent. A sociological argument is that wives' employment might be contrary to traditional role expectations emphasizing women's role as homemakers. The wife's work could therefore lead to conflicts and competition, or threaten the husband's role as main provider (Parsons, 1949; Vannoy and Philliber, 1992). Being employed might also provide women with greater self-esteem (Kessler and McRae, 1982), which increases her social-psychological independence, making it easier to divorce (Esterberg et al., 1994), possibly also for husbands.

An alternative interpretation of the positive work effect is that the perceived divorce risk affects wives' labour market behaviour; women respond to a heightened divorce risk by adjusting their working hours in preparation for divorce. It is usually assumed that women increase their working efforts prior to divorce (Beck and Hartmann, 1999; Johnson and Skinner, 1986; Rogers, 1999), but women might also not change their working hours, whereas otherwise - if they were to stay married - they would have worked less. Such adjustments imply that women work more hours in the years before divorce than if they were to stay married. These anticipatory adjustments lead to a positive association between wives' work and divorce but now it is not a 'causal' effect of wives' work but the result of wives' anticipatory adjustments. A common argument for these adjustments is that women want to be able to financially support themselves after divorce (Diekmann, 1994; Johnson and Skinner, 1986; Rogers, 1999). A less common argument is that women increase or retain their working hours, because they already want to become less dependent upon the marriage in a socialpsychological sense (Rogers, 1999).

Because women's ability to react to a heightened divorce risk is likely to vary depending upon the extent to which women expect the divorce, it is possible to develop hypotheses about differences in the effect of wives' work between divorces that vary in this respect. A plausible assumption is that women for whom the divorce was fully unexpected were probably not able to adjust their working hours at all, whereas women for whom the divorce was fully expected were best able to 
do so. That is, the more women expect to divorce, the greater the role of anticipatory behaviour. Stated differently, when women do not expect to divorce, anticipatory behaviour is controlled for and cannot be responsible for a work effect, whereas for women expecting to divorce anticipatory behaviour may be responsible for a work effect. Hence, if women indeed make anticipatory adjustments, the relation between wives' work and divorce should be stronger, the more women expected the divorce. Taking the argument a step further, if anticipatory behaviour were solely responsible for the higher divorce risk of working women, there would be no positive effect of wives' work when women did not expect to divorce.

The alternative interpretation arguing that wives' work increases the divorce risk might hold as well. If it is also true that wives' employment increases the risk of divorce, one would expect that there continues to be a higher divorce risk among working women when the divorce was unexpected. Taking the argument a step further, if this interpretation of the work effect was solely responsible for the positive association between wives' work and divorce, the effects of wives' work should be the same for expected and unexpected divorces. The higher divorce risk of working women is then likely to be due to other reasons than anticipatory behaviour, which have been put forward to explain why wives' work increases the risk of divorce. However, some of these reasons may be less plausible when women did not expect the divorce. Employed women's greater financial or social-psychological independence is probably not such a relevant consideration when they do not expect to divorce; these forms of independence resulting from the wife's work imply that she perceives her employment as facilitating divorce and such considerations are likely to be relevant only when women are actually aware that their marriage is in trouble. The other reasons might, however, still hold; even when women did not expect to divorce, their employment might lead to a higher divorce risk because of smaller efficiency gains, because their work is contrary to traditional role expectations, or husbands might more easily divorce when their wives work. ${ }^{1}$

\section{Data}

I use the survey 'Divorce in the Netherlands 1998' (SIN98; Kalmijn et al., 2000), which is based on a stratified sample design in two steps. First, a select sample of 19 municipalities was drawn, which were representative of the Dutch population with respect to urbanization and region. Second, three random samples were drawn from these municipalities: (a) people in their first marriage, (b) divorced people who did not remarry, and (c) divorced people who remarried. This design leads to an over-representation of ever-divorced persons. The sample does not include widowed persons and persons who cohabit or separated from a cohabiting union, and consists of 2346 persons ( 77 per cent divorced).

Because the focus is on wives' work, only female respondents are selected and they have to be in either their first marriage or divorced from their first marriage. After excluding cases with missing values on central variables (timing of divorce, marriage and employment), the selection consists of 1285 women, who married between 1943 and 1997 and divorced between 1949 and 1998. In face-to-face interviews, respondents provided retrospective information about their complete employment history and work characteristics of their (former) spouse. Because spousal information is obtained from the respondent, it is less detailed than information about the respondent. Divorced respondents were also retrospectively questioned about the process of divorce, one of the questions being to what extent they expected the decision to divorce.

\section{Analytical Strategy and Measurements}

First, I examine whether women who work or work more hours are more likely to divorce, because such positive associations are a necessary condition for both directional relationships to exist. Discrete-time event history analysis is used (Allison, 1984; Yamaguchi, 1991), which comes down to applying logistic regression on a person-period file containing a record for each person for every year in which this person is at risk of divorce. The file starts with the year of marriage and ends in the year the decision was taken to divorce for ever-divorced persons or the survey year if persons remain married. Most studies look at the time at which the couple stopped living together, but I use the timing of the divorce decision because the question about the expectedness of divorce refers to the decision. I also want to eliminate the possibility that women adjust their working efforts in the period between the decision and the actual break-up. This is a form of adjustment comparable to what women do after divorce that is not of theoretical interest here and would lead to an overestimation of the work effect. The 1285 female respondents 
contribute to a total of 19,502 person-years and 1000 divorces. Because logistic regression techniques are insensitive to sampling on the dependent variable, the over-representation of divorced persons does not bias the coefficients (Allison, 1999). The dependent variable is the conditional probability of divorce in a given year, provided that persons are still at risk of divorce. As said, divorce refers to the divorce decision. The central independent variables are: (1) whether the wife works, (2) whether she works part-time or full-time, and (3) the number of working hours. Because wives' work is correlated with husbands' labour market characteristics and economic characteristics of the household, I control for the husband's work and the household's financial situation. The analyses also control for other well-known determinants of divorce. Details about these control variables, their measurement and descriptive information can be found in Table 1, as well as information about the central independent variables. The last column of Table 1 shows the results for an event-history model of divorce including only the control variables. These results are generally in line with previous findings.

Second, I compare the effects of wives' work between divorces that differ in the extent to which they were expected. The different types of divorces were measured by asking divorced women retrospectively: 'Did the decision to break up come unexpectedly or did you see it coming?' They could choose from the following answers: (1) fully unexpected, (2) rather unexpected (3) rather expected, and (4) fully expected. About 55 per cent fully expected to divorce. Also, the number of women who rather expected the divorce is relatively high (22 per cent). The divorce was fully unexpected for 14 per cent of the women and rather unexpected for another 9 per cent. The high percentages of fully and rather expected divorces might be due to the retrospective nature of the question. In hindsight, most women will realize that there were already indications that the marriage was in trouble. Therefore, women who did not actually see the divorce coming at the time may be incorrectly classified as expecting the divorce using this retrospective question. An advantage, however, is that misclassification is unlikely for women who even retrospectively indicate that they did not expect to divorce at all (fully unexpected divorces). Anticipatory behaviour can therefore be ruled out as accounting for a possible work effect among this group of women. As explained, another issue may be that a comparison of the effects of wives' work might be a rather conservative test of whether wives' work in itself leads to a higher divorce risk; differences in work effects between expected and unexpected divorces might not only be due to differences in anticipatory behaviour, because some of the reasons why wives' work increases the risk of divorce (i.e. financial or socialpsychological independence) might also hold to a lesser extent when the divorce was unexpected. The misclassification of women not anticipating the divorce into the category of expected divorces, however, might also imply a rather conservative test of anticipatory behaviour, because the inclusion of women actually not expecting the divorce in the category of expected divorces may lead to an underestimation of the effect of anticipatory behaviour as estimated by the work effect for expected divorces.

The effects of wives' work are estimated by using competing risk event history analysis (Allison, 1984), in which the different types of divorces are treated as different events and the other types are treated as a competing risk. This method comes down to applying multinomial logistic regression on the person-period file, in which the four kinds of divorces are treated as separate categories of the dependent variable. As a result, there are four dependent variables: the conditional probability of a (1) fully unexpected divorce, (2) rather unexpected divorce (3) rather expected divorce, and (4) fully expected divorce (all versus staying married). The analyses include the control variables in Table 1. I also test whether the effect of wives' work/working hours linearly increases when the divorce is more expected. If anticipatory behaviour is (partly) responsible for working wives' higher divorce risk, the effects should increase in a linear fashion. Linear constraints that constrain differences in the effects to be equal are imposed upon on the model and tested using a likelihood ratio test. ${ }^{2} \mathrm{I}$ also test whether the effects are equal for the four types of divorces. I estimate a model in which the effects are constrained to be equal and test these constraints by means of a likelihood ratio test. If the effects do not differ significantly, anticipatory behaviour does not seem to be strong enough to lead to systematic differences in the effects of wives' work. This would lend strong support for the alternative interpretation that wives' work increases the divorce risk.

\section{Results}

The second column in Table 2 shows the results of the discrete-time event history analysis for the overall risk of divorce. The upper panel examines the effect of wife's employment on the probability of divorce; working women have a 16 per cent $\left(e^{0.148}-1\right)$ higher odds of 
Table 1 Definitions, means and standard deviations (in parentheses) of the central independent and control variables, and results from the event history analyses for the baseline model

$\begin{array}{cc}\begin{array}{c}\text { Mean } \\ \text { (standard } \\ \text { deviation) }^{\mathrm{a}}\end{array} & \begin{array}{c}\text { Baseline } \\ \text { model }\end{array} \\ \end{array}$

Whether wife works

(Dynamic variable whether wife works, referring to the year before the risk year. If wife's work is not lagged by one year the effect would be overestimated due to women who started to work (more) just after divorce)

Part-time work

(Dynamic variable whether wife works 1-34 hours versus not working, lagged)

Full-time work

(Dynamic variable whether wife works over 34 hours versus not working, lagged)

Working hours

(Dynamic variable for number of weekly working hours, 0-40, lagged)

Control variables

Period

(Dynamic variable for calendar year, from $1943(=0)$ to 1998 (= 55). A linear specification fits the data best)

Marital duration

(Duration of marriage in years. A non-linear specification fits the data best)

Marital duration squared

Youngest child 6 years old or younger

(Dynamic variable whether youngest child living at home is 6 years old or younger versus no children)

Youngest child between 6 and 12 years old

(Dynamic variable whether youngest child is 6-12 years old versus no children)

Youngest child over 12 years old

(Dynamic variable whether youngest child is more than 12 years old versus no children)

Children left the parental home

(Dynamic variable whether children left the parental home versus no children)

Wife married before age 21

Religiosity

(Scale counting whether wife was church member at start of marriage, whether she

attended church often and whether her mother was church member, 0-3)

Whether wife's parents divorced when wife was growing up

Cohabited with current or former spouse before marrying

Living in a city during first years of marriage

Whether husband works during first years of marriage

Number of financial problems during first years of marriage (0-6)

Wife's education

(Dynamic variable for most recent and highest educational level in years, 6-16)

Husband's education

(Highest completed educational level in years, 6-16)

Number of persons

Number of person-years

Number of events

Log likelihood

Chi2 (df) $0.80^{\mathrm{b}}$

$0.11^{\mathrm{b}}$

$30.29^{\mathrm{b}}$

$30.07^{\mathrm{b}}$

(10.96)

0.00

$(0.00)$

$0.00^{\mathrm{b}}$

$(0.00)$

$0.13^{\mathrm{b}}$

$0.054^{\star}$

$-0.564^{\star}$

$0.00^{\mathrm{b}} \quad-0.418^{\star}$

$0.00^{\mathrm{b}} \quad-0.064$

$0.00^{\mathrm{b}} \quad 0.105$

$0.24 \quad 0.179^{\star}$

$1.48-0.170^{*}$

(1.04)

$\begin{array}{ll}0.08 & 0.281^{*}\end{array}$

$0.35 \quad 0.343^{*}$

$0.69 \quad 0.337^{*}$

$0.85^{\mathrm{b}}-0.354^{*}$

$1.14 \quad 0.065^{*}$

(1.52)

$11.35^{\mathrm{b}}$

$0.061^{\star}$

(2.85)

11.47

(3.09)

$-0.041^{\star}$

1285

19,502

1000

$-3649$

$590(16)$ $0.70^{\mathrm{b}}$

${ }^{a}$ Standard deviations not reported for dichotomous variables.

${ }^{b}$ Time-varying variable (the mean refers to the first year of marriage).

${ }^{*} P<0.05, \sim P<0.10$. 
Table 2 The relation between wives' work and divorce (discrete-time event history models) and differences between expected and unexpected divorces (competing risk analyses)

\begin{tabular}{|c|c|c|c|c|c|c|c|}
\hline & \multirow{2}{*}{$\begin{array}{c}\text { Event } \\
\text { history } \\
\text { model }^{\text {a }} \\
\text { Overall } \\
\text { divorce } \\
\text { risk }\end{array}$} & \multicolumn{4}{|c|}{ Competing risk model ${ }^{b}$} & \multicolumn{2}{|c|}{ Likelihood ratio tests } \\
\hline & & $\begin{array}{c}\text { Fully } \\
\text { unexpected }\end{array}$ & $\begin{array}{c}\text { Rather } \\
\text { unexpected }\end{array}$ & $\begin{array}{l}\text { Rather } \\
\text { expected }\end{array}$ & $\begin{array}{c}\text { Fully } \\
\text { expected }\end{array}$ & $\begin{array}{c}\text { Test linear } \\
\text { relation between } \\
\text { effects }^{c}\end{array}$ & $\begin{array}{c}\text { Test } \\
\text { equality } \\
\text { effects }^{d}\end{array}$ \\
\hline $\begin{array}{l}\text { Wife's work } \\
\text { Model fit }\end{array}$ & $0.148^{*}$ & 0.233 & -0.180 & 0.162 & $0.174 \sim$ & 2.22 & 2.31 \\
\hline Log likelihood & -3647 & & & & -4768 & & \\
\hline Chi2 (df) & $595(17)$ & & & & $658(68)$ & & \\
\hline Wife's part-time work & 0.058 & 0.261 & -0.435 & 0.070 & 0.075 & 4.09 & 3.86 \\
\hline $\begin{array}{l}\text { Wife's full-time work } \\
\text { Model fit }\end{array}$ & $0.255^{\star}$ & 0.192 & 0.067 & 0.271 & $0.288^{\star}$ & & \\
\hline Log likelihood & -3645 & & & & -4765 & & \\
\hline Chi2 (df) & $599(18)$ & & & & $665(72)$ & & \\
\hline $\begin{array}{l}\text { Wife's working hours } \\
\text { Model fit }\end{array}$ & $0.007^{\star}$ & 0.007 & -0.001 & 0.005 & $0.008^{\star}$ & 1.24 & 1.70 \\
\hline Log likelihood & -3645 & & & & -4766 & & \\
\hline Chi2 (df) & $599(17)$ & & & & $662(68)$ & & \\
\hline
\end{tabular}

${ }^{a}$ Number of persons: 1285; number of person-years: 19,502; number of divorces: 1000.

${ }^{b}$ Number of persons: 1284; number of person-years: 19,495; number of fully unexpected divorces: 136; number of rather unexpected divorces: 93; number of rather expected divorces: 223; number of fully expected divorces: 547.

${ }^{c}$ Likelihood ratio test of whether the effects are linearly related: Chi2 statistic.

${ }^{d}$ Likelihood ratio test of whether the effects are equal: Chi2 statistic.

${ }^{*} P<0.05, \sim P<0.10$.

Notes: models include the control variables in Table 1. Number of persons and person-years differs between the models for overall divorce and for different types of divorces due to missing values on expectedness of divorce.

divorce than non-working women. In the middle panel a distinction is made between part-time and full-time work. Only women who work full-time have a higher risk of divorce. Compared to non-working women, those with a full-time job have a 29 per cent higher odds of divorce. The lower panel shows the results for the wife's number of working hours. In line with the above, women who work more hours are found to have a higher divorce risk.

Table 2 also shows the results of the competing risk analyses, in which a distinction is made between four types of divorce. The last two columns of Table 2 present the results of the likelihood ratio tests for a linear relation between the effects of wives' work, and for their equality, respectively. Because the significance of the work effects depends upon the number of events (Allison, 1984), the effects are more likely to be significant for rather and fully expected divorces. It is therefore more instructive to look at the size of the effects and the results of the likelihood ratio tests.

The upper panel of Table 2 shows the results for wives' employment. If the effects of wives' work become stronger the more the divorce was expected, the interpretation of anticipatory behaviour finds support. However, if the effects are more or less similar and the divorce risk continues to be higher for working women when the divorce was unexpected, the interpretation that wives' work increases the risk of divorce is plausible as well. The results show no clear increase in the effect of wives' work when the divorce becomes more expected. Only when the divorce was rather unexpected is there no positive effect of wives' work, but note that this group is relatively small. Although this finding lends some support for anticipatory behaviour, the effects for the other three types of divorces are positive and more or less similar. In fact, the effect of wives' work is strongest when the divorce was fully unexpected. Because this group of women was least able to make anticipatory labour market adjustments, the strong effect for fully unexpected divorces does not support the idea of anticipatory behaviour but rather that wives' work leads to a higher divorce risk. The results for a model with linear constraints (not presented) show that the effect of 
wives' work increases from 0.106 for fully unexpected divorces to 0.162 for fully expected divorces. A test of these linear constraints is insignificant, suggesting that this linear increase cannot be rejected. However, a test of the special case of linearity that all coefficients are equal cannot be rejected either. ${ }^{3}$ The finding that the effects do not differ in combination with the finding that the effect of wives' work is strongest when the divorce was fully unexpected suggests that differences in anticipatory behaviour are not large enough to lead to systematic differences in the effects of wives' work. The results therefore lend strong support for the alternative interpretation that wives' work increases the risk of divorce.

The middle panel shows that the effects of part-time work fluctuate, and are not in line with the interpretation of anticipatory behaviour. However, the effect of part-time work was not significant to begin with, and only full-time working women were significantly more likely to divorce. The results for full-time work are to some extent consistent with the idea of anticipatory behaviour. The effects of full-time work are stronger for fully and rather expected divorces than for fully and rather unexpected ones. However, the effect of full-time work is also relatively strong when the divorce was fully unexpected, whereas this group of women was least able to adjust their work hours. When linear constraints are imposed, the effect of full-time work increases from 0.154 (fully unexpected) to 0.288 (fully expected). The likelihood ratio test shows that this linearly constrained model cannot be rejected, which lends some support for the idea of anticipatory behaviour. However, as before, the likelihood ratio test for the equality of effects is also insignificant, suggesting that there are no systematic differences in the effect of full-time work (and part-time work) between the different types of divorce. The similarity of the effects and the relatively strong effect of wives' full-time work when the divorce was fully unexpected, suggests that anticipatory behaviour does not fully explain the higher divorce risk of full-time working women and that there is also something about wives' work making divorce more likely.

Finally, the results for the number of working hours in the lower panel reveal no systematic increase in the effect of working hours when the divorce becomes more expected. Only the null-effect for rather unexpected divorces lends some support for the idea of anticipatory behaviour. However, the effect of working hours is relatively strong in the case where the divorce was fully unexpected, which supports the interpretation that wives' work leads to an increase in the risk of divorce. A linearly constrained model, in which the effect of wives' working hours increases from 0.004 to 0.008 , cannot be rejected. However, a constrained model with equal effects cannot be rejected either. These findings lend strong support for the interpretation that wives' work increases the divorce risk.

\section{Conclusion and Discussion}

Women who work or work more hours were found to have a higher divorce risk than women who do not work or work less. Particularly full-time working women have a higher divorce risk. This positive association between wives' work and divorce might be the result of a higher divorce risk when women work or of wives' labour market reactions in anticipation of divorce (reversed causation). These competing hypotheses have been tested by comparing the effect of wives' work on divorce between divorces varying in the extent to which they were expected.

The findings lend weak support for anticipatory behaviour. The effect of wives' full-time work is smaller when the divorce was unexpected than when it was expected. Because women who did not expect to divorce were probably not able to make labour market adjustments in anticipation of divorce, the effect of anticipatory behaviour is cancelled out for unexpected divorces. The smaller effect of wives' full-time work on unexpected divorces therefore lends some support for the interpretation that the higher divorce risk of full-time working women is due to anticipatory behaviour.

However, there is also strong evidence that wives' work increases the risk of divorce. The effect of full-time work is relatively strong when the divorce was fully unexpected. In addition, the effects of being employed and the number of working hours are even stronger (or equally strong) for fully unexpected divorces than for rather or fully expected divorces. Finally, although it could not be rejected that the effects of wives' work linearly increase when the divorce was more expected, the special case of equal effects could not be rejected either. Because the effects do not differ significantly for the different kinds of divorce, differences in anticipatory behaviour are not great enough to lead to systematic differences in the effects of wives' work. These findings strongly suggest that there is something about wives' work that increases the risk of divorce.

The results of this study are comparable to the findings for Germany (Beck and Hartmann, 1999) and opposite to American findings (Johnson and Skinner, 
1986; Rogers, 1999). The reason why greater support for anticipatory behaviour is found for the United States than for Germany and the Netherlands might be that the latter countries are characterized by a more extensive welfare system. Relatively high welfare benefits mean that paid employment is not necessarily required to provide for one's family after divorce. In more extensive welfare systems as the Netherlands it is therefore less necessary for women to adjust their working efforts prior to divorce to ensure their financial security afterwards.

The contrasting findings might also result from differences in methodology; American findings are based on statistical models estimating reciprocal paths, whereas the German and Dutch findings are based on substantive reasoning leading to procedures that try to eliminate the role of anticipatory behaviour. Each of these methods has its pros and cons. In this study, the reliability and validity of the used measure for the different kinds of divorces may have been reduced, because this measure is retrospective and based on only one question. Although the possibility exists that women who did not see the divorce coming at that time are incorrectly classified as expecting to divorce in retrospect - possibly leading to an underestimation of the effect of anticipatory behaviour for expected divorces - the advantage is that such misclassifications are unlikely for fully unexpected divorces. As a result, anticipatory behaviour is unlikely to be responsible for the relatively strong work effects found for the group of women who in hindsight admit that they did not expect to divorce at all. If one also takes into account that some of the reasons why wives' work leads to a heightened divorce risk are less likely to hold when the divorce is unexpected, the destabilizing influence of wives' work in itself may be even larger than the results for fully unexpected divorces suggest. The possible retrospective bias has also led to a relatively small number of women who did not expect to divorce, which may have reduced the power of the models.

Despite these problems, the development and testing of new substantive hypotheses to examine the direction of the relationship may be a promising strategy. Some of the problems of the retrospective design used in this study might be solved with prospective data. It would therefore be worthwhile to test the hypotheses with panel data and see whether the influence of wives' work systematically varies with the extent to which women expect to divorce beforehand. Such panel data also offer the possibility to test one of the assumptions made here directly: do women indeed adjust their working efforts when they expect to divorce in the future? Although the assumption that only women who expected to divorce could adjust their working hours is plausible, the question is whether they indeed do so. Using women's own subjective reports on their chances of divorce as predictors for their future labour supply, would also improve upon models based on simultaneous estimation, since they use estimated objective divorce risks as predictors. Given the few studies on the direction of the relationship between wives' work and divorce and the mixed findings, future research using a wide variety of methods is needed to more conclusively address this issue, preferably on the basis of panel data from different countries with varying welfare regimes.

\section{Notes}

1. Even some of these remaining arguments might hold to a lesser extent for women who do not expect to divorce. For example, if wives' work opposes traditional role expectations and results in tensions/ conflicts, women who did not expect the divorce might also have experienced fewer conflicts. However, a violation of traditional norms does not necessarily have to lead to overt conflicts and the amount of conflict does not have to be related to the extent to which women expect to divorce. Further analyses show that the number of conflicts during the first years of marriage does not vary systematically with the extent to which the divorce was expected. The differences in conflict between women who subsequently divorce and those who remain married are larger than differences between women who differ in the extent to which they expected the divorce. Only women who fully expected the divorce report more conflicts, whereas conflict does not differ between women for whom the divorce was fully unexpected, rather unexpected or rather expected.

2. The simultaneously imposed linear restrictions are: effect wife's work (fully unexpected) - effect wife's work (rather unexpected) $=$ effect wife's work (rather unexpected) - effect wife's work (rather expected) = effect wife's work (rather expected) - effect wife's work (fully expected). The equality constraints are: effect wife's work (fully unexpected) = effect wife's work (rather unexpected) $=$ effect wife's work (rather expected) $=$ effect wife's work (fully expected).

3. To increase the power of the models, I also made a distinction between rather and fully unexpected divorces, on the one hand, and rather and fully expected divorces, on the other hand. Although the differences in effects become larger, a test of whether 
the effects are equal shows that this hypothesis cannot be rejected.

\section{Acknowledgements}

This research was supported by Utrecht University and the Netherlands Organization for Scientific Research (NWO, 510-05-0602). I thank Matthijs Kalmijn, Paul de Graaf and the anonymous reviewers for their helpful comments.

\section{References}

Allison, P. D. (1984). Event history analysis. Regression for longitudinal event data. Beverly Hills: Sage Publications.

Allison, P. D. (1999). Logistic regression using the SAS system. Theory and application. Cary: SAS Institute.

Beck, N. and Hartmann, J. (1999). Die Wechselwirkung zwischen Erwarbstätigkeit der Ehefrau und Ehestabilität unter der Berücksichtigumg des sozialen Wandels. Kölner Zeitschrift für Soziologie und Sozialpsychologie, 51, 655-680.

Becker, G. S. (1981). A treatise on the family. Cambridge: Harvard University Press.

Bracher, M., Santow, G., Morgan, M. and Trussel, J. (1993). Marital dissolution in Australia: Models and explanations. Population Studies, 47, 403-425.

Cherlin, A. (1979). Work life and marital dissolution. In Levinger, G. and Moles, O. C. (Eds) Divorce and separation: Context, causes and consequences. New York: Basic Books, pp. 151-166.

Cherlin, A. (1981), Marriage, divorce, remarriage. Cambridge: Harvard University Press.

Davis, K. (1984). Wives and work: The sex role revolution and its consequences. Population and Development Review, 10, 397-417.

Diekmann, A. (1994). Hat das steigende Ehescheidungsrisiko das berufliche Engagement von Frauen gefördert? Soziale Welt, 45, 83-97.

Esterberg, K. G., Moen, P. and Dempster-McCain, D. (1994). Transition to divorce: A life-course approach to women's marital duration and dissolution. The Sociological Quarterly, 35, 289-307.
Greenstein, T. N. (1990). Marital disruption and the employment of married women. Journal of Marriage and the Family, 52, 657-676.

Johnson, W. R. and Skinner, J. (1986). Labor supply and marital separation. American Economic Review, 76, 455-469.

Kalmijn, M., De Graaf, P. M. and Uunk, W. (2000). Codeboek Scheiding in Nederland 1998. Utrecht: ICS Occasional Papers and Document Series, ICS Codebooks-40.

Kessler, R. C. and McRae, J. A. Jr. (1982). The effect of wives' employment on the mental health of married men and women. American Sociological Review, 47, 216-227.

Parsons, T. (1949). The social structure of the family. In Anshen, R. (Ed.) The family: Its function and destiny. New York: Harper and Brothers, pp. 173-201.

Rogers, S. J. (1999). Wives' income and marital quality: Are there reciprocal effects? Journal of Marriage and the Family, 61, 123-132.

Ruggles, S. (1997a). The rise of divorce and separation in the United States, 1880-1990. Demography, 34, 455-466.

Ruggles, S. (1997b). Reply to Oppenheimer and Preston. Demography, 34, 475-479.

South, S. J. (2001). Time-dependent effects of wives' employment on marital dissolution. American Sociological Review, 66, 226-245.

Spitze, G. and South, S. J. (1985). Women's employment, time expenditure and divorce. Journal of Family Issues, 6, 307-329.

Vannoy, D. and Philliber, W. W. (1992). Wife's employment and quality of marriage. Journal of Marriage and the Family, 54, 387-398.

Yamaguchi, K. (1991). Event history analysis. Newbury Park: Sage Publications.

\section{Author's Address}

Department of Social-Cultural Sciences, Vrije Universiteit Amsterdam, De Boelelaan 1081, $1081 \mathrm{HV}$ Amsterdam, The Netherlands. Tel.: +31 20 5986720; Fax: +31 20 5986810; Email: ar.poortman@fsw.vu.nl

Manuscript received: June 2003 